TEXTO FUNDAMENTAL

\title{
NEO-INSTITUCIONALISMO: FATORES ORGANIZACIONAIS NA VIDA POLÍTICA ${ }^{1}$
}

James G. March

\author{
Johan P. Olsen
}

\begin{abstract}
RESUMO
As teorias políticas contemporâneas tendem a retratar a política como um reflexo da sociedade; os fenômenos políticos como as conseqüências agregadas do comportamento individual; a ação como o resultado de escolhas baseadas no interesse pessoal calculado; a história como sendo eficiente no alcance de desfechos singulares e adequados e a tomada de decisões e a alocação de recursos como os focos centrais da vida política. Entretanto, um pensamento teórico recente na Ciência Política combina elementos desses estilos teóricos com uma preocupação mais antiga a respeito das instituições. Esse neo-institucionalismo enfatiza a autonomia relativa das instituições políticas, as possibilidades de ineficiência na história e a importância da ação simbólica para um entendimento da política. Tais idéias possuem uma razoável base empírica, mas não se caracterizam por formas teóricas poderosas. Entretanto, pode-se identificar algumas direções para a pesquisa teórica nas concepções institucionalistas da ordem política: esse é o nosso objetivo neste artigo.
\end{abstract}

PALAVRAS-CHAVE: neo-institucionalismo; autonomia das instituições; ação simbólica; eficiência da ação

\section{INTRODUÇÃO2}

Na maior parte das teorias políticas contemporâneas, as instituições políticas tradicionais, tais como a legislatura, o sistema legal e o Estado, assim como as instituições econômicas tradicionais, como a firma, perderam importância em relação à posição que tinham nas teorias anteriores de cientistas políticos como J. W. Burgess ou W. W. Willoughby, economistas como Thorstein

1 Este artigo é uma tradução do texto “The New Institutionalism: Organizational Factors in Political Life”, publicado originalmente em The American Political Science Review, v. 78, n. 3, p. 734-749, Sept.1984. Agradecemos a gentil autorização da editora da Universidade de Cambridge, que detém os seus direitos, para traduzi-lo e publicá-lo. Tradução de Gustavo Rinaldi Althoff e revisão da tradução de Tiago Losso e de Gustavo Biscaia de Lacerda (nota do tradutor).

2 Esta pesquisa teve o apoio das bolsas do Norwegian Research Council for Science and Humanities, do Norwegian Ministry of Consumer Affairs and Government Administration, da Mellon Foundation, da Spencer Foundation, da Stanford Graduate School of Business e da Hoover Institution. Somos gratos pelos comentários de Julia W. Ball, Michael D. Cohen, Stephen D. Krasner, Martin Landau, Todd LaPorte, W. Richard Scott e William Siffin.
Veblen ou John R. Commons e sociólogos como Max Weber. De um ponto de vista comportamental, as instituições sociais formalmente organizadas passaram a ser retratadas simplesmente como arenas dentro das quais o comportamento político, motivado por fatores mais fundamentais, ocorre. De um ponto de vista normativo, idéias que embutiam moralidade nas instituições, tais como as da lei ou da burocracia, e que enfatizavam a cidadania como um fundamento para a identidade pessoal, deram lugar a idéias de moralismo individual e a uma ênfase em interesses conflitantes.

Entretanto, em anos recentes, um novo institucionalismo surgiu na Ciência Política. Ele está longe de ser coerente ou consistente e não está completamente legitimado, mas também não pode ser inteiramente ignorado. $\mathrm{O}$ ressurgimento dessa preocupação com as instituições é uma conseqüência cumulativa da moderna transformação das instituições sociais e do persistente comentário de seus observadores. As instituições sociais, políticas e econômicas tornaram-se maiores, consideravelmente mais complexas e cheias de recursos e, prima facie, mais importantes para a vida coletiva. A maioria dos principais atores nos sistemas econômicos e políticos modernos são organizações formais e as instituições da lei e da 
burocracia ocupam um papel dominante na vida contemporânea.

A atenção às instituições políticas aumentou na literatura sobre legislaturas (SHEPSLE \& WEINGAST, 1982), orçamentos (PADGETT, 1981), elaboração de políticas públicas (ASHFORD, 1977; SCHARPF, 1977), governo local (KJELBERG, 1975) e elites políticas (ROBINS, 1976). Ela encontra-se manifesta em estudos sobre a origem do Estado (WRIGHT, 1977) e sobre o desenvolvimento da capacidade administrativa nacional (SKOWRONEK, 1982), em análises do colapso de regimes democráticos (POTTER, 1979) e em discussões sobre o corporativismo (SCHMITTER \& LEHMBRUCH, 1979; BERGER, 1981; OLSEN, 1981). Ela reflete-se em duas redescobertas marxistas: do Estado como um problema dentro da Economia Política (JESSOP, 1977) e da importância dos fatores organizacionais para o entendimento desse papel (THERBORN, 1980). Ela está presente em estudos sobre organizações formais e, particularmente, em estudos sobre o lugar de tais organizações na implementação de políticas públicas [public policy] (HANF \& SCHARPF, 1978); está visível nas tentativas de conexão do estudo do Estado à ciência natural (MASTERS, 1983) e às humanidades (GEERTZ, 1980), assim como em um renovado interesse na execução de estudos histórico-comparativos sobre o Estado (HAYWARD \& BERKI, 1979; EVANS, RUESCHEMEYER \& SKOCPOL, 1983; KRASNER, 1984).

Neste artigo examinamos alguns aspectos desses desenvolvimentos e suas implicações para desenvolver-se um entendimento teórico a respeito de como a vida política é organizada. Abordamos essa tarefa da perspectiva dos estudiosos das organizações formais. Entretanto, o argumento estende-se para além da teoria das organizações, na direção de uma visão mais geral do lugar das instituições na política e das possibilidades para uma teoria política atenta a elas.

\section{OS ESTILOS TEÓRICOS DA CIÊNCIA PO- LÍTICA CONTEMPORÂNEA}

Embora o conceito de "instituição" jamais tenha desaparecido da Ciência Política teórica, a visão fundamental que caracterizou as teorias políticas desde aproximadamente 1950 é (a) contextual, inclinada a ver a política como uma parte integral da sociedade e menos inclinada a diferenciar o Estado politicamente organizado [polity $^{3}$ do resto da sociedade; (b) reducionista, inclinada a ver os fenômenos políticos como as conseqüências agregadas dos comportamentos individuais e menos inclinada a atribuir os resultados da política às estruturas organizacionais e às regras de comportamento adequado; (c) utilitária, inclinada a ver a ação como o produto do interesse pessoal calculado e menos inclinada a ver os atores políticos como respondendo a obrigações e deveres; (d) funcionalista, inclinada a ver a história como um mecanismo eficiente no alcance de equilíbrios singularmente adequados e menos preocupada com as possibilidades de inadaptação e não-singularidade no desenvolvimento histórico e (e) instrumentalista, inclinada a definir a tomada de decisões e a alocação de recursos como as preocupações centrais da vida política e menos atenta às maneiras pelas quais a vida política está organizada em torno do desenvolvimento de significados, por meio de símbolos, rituais e cerimônias.

\section{II.1. A política como subordinada a forças} exógenas: o contextualismo

Historicamente, os cientistas e filósofos políticos tenderam a tratar as instituições políticas particularmente o Estado - como fatores independentes, importantes para o ordenamento e o entendimento da vida coletiva (HELLER, 1957 [1933]). Os cientistas políticos modernos, com poucas exceções, não. O Estado perdeu sua posição de centralidade na disciplina; o interesse em formas abrangentes de organização política declinou; os eventos políticos são definidos mais como epifenômenos do que como ações necessárias para ter-se um entendimento da sociedade; a política espelha o seu contexto (EASTON, 1968).

\footnotetext{
3 A palavra inglesa polity vem da palavra grego "politéia”, termo de significado incerto. Uns definem-na como todo e qualquer tipo de ordem política, exceto a tirania (que não é ordem política), outros como um tipo específico de ordem política, a república. Poderia ser traduzida como "sistema político”, “ordem política”, “instituições políticas” ou “organização política”; contudo, os correlatos desses termos em inglês aparecem no original - political system, political order, political institutions e political organization-, dificultando a tradução de polity por quaisquer um deles. Assim, cremos que a expressão "Estado politicamente organizado” transmite com precisão o conceito (N. T.).
} 
O fator contextual mais conspícuo citado em escritos recentes é o da estrutura de classes sociais. A estratificação social de uma sociedade moderna, com sua distribuição de riqueza e renda associada, possui grandes e óbvios efeitos nos eventos políticos. As diferenças de classe traduzem-se em diferenças políticas com grande confiabilidade, através do tempo e traspassando culturas; as diferenças na organização e na ideologia das classes sociais parecem conduzir a diferenças previsíveis nas organizações e nas instituições políticas (TILLY, 1978). Outras análises, no mesmo nível de agregação, tornam a estrutura e o processo da política uma função do ambiente físico, da geografia e do clima; da etnicidade, da língua e da cultura; das condições econômicas e do desenvolvimento, ou da demografia, da tecnologia, da ideologia ou da religião. Desenvolveram-se argumentos plausíveis que tornam a vida política um derivativo de uma ou mais dessas forças contextuais abrangentes e não é difícil encontrar dados empíricos para apoiar esses argumentos. Embora haja uma quantidade de teorias contextuais relativamente precisas, do presente ponto vista a principal significância teórica dessas idéias são menos as formas específicas das teorias do que sua inclinação geral em perceber as conexões causais entre a sociedade e o Estado politicamente organizado como se movendo daquela para este, em vez de na direção oposta. Supõe-se que classe, geografia, clima, etnicidade, língua, cultura, condições econômicas, demografia, tecnologia, ideologia e religião - todos afetam a política, mas não são significativamente afetados por ela.

\section{II.2. As macroconseqüências de microcomporta-} mentos: o reducionismo

Historicamente, a Teoria Política tratou as instituições políticas como determinando, ordenando ou modificando as motivações dos indivíduos e como agindo autonomamente em termos de necessidades institucionais. Por outro lado, elementos substanciais de modernos trabalhos teóricos na Ciência Política supõem que os fenômenos políticos são mais bem entendidos como as conseqüências agregadas de comportamentos compreensíveis nos níveis do indivíduo ou do grupo.

Tais teorias baseiam-se em duas pressuposições. A primeira pressuposição é a de que um sistema político consiste em um número (freqüentemente grande) de atores elementares.
No nível desses atores elementares, o comportamento humano pode ser visto como consciente, calculado e flexível ou como inconsciente, habitual e rígido. Em um ou outro caso, as preferências e os poderes dos atores são exógenos ao sistema político, dependendo de suas posições no sistema social e econômico. A segunda pressuposição é a de que o comportamento coletivo é mais bem entendido como se originando do entrelaçamento de comportamentos (possivelmente intrincados) compreensíveis em um nível mais baixo de agregação. A descoberta, ou a dedução, das conseqüências coletivas pode ser difícil ou mesmo impossível, mas a crença central é de que os resultados, no nível coletivo, dependem somente das complexidades das interações entre os atores individuais, que os conceitos que sugerem comportamento autônomo no nível agregado são certamente supérfluos e provavelmente deletérios.

Em tal perspectiva, por exemplo, o comportamento de uma organização é a conseqüência das escolhas entrelaçadas feitas por indivíduos e subunidades, cada qual agindo em termos de suas expectativas e preferências manifestadas nesses níveis (NISKANEN, 1971). O comportamento de um mercado é a conseqüência das escolhas entrelaçadas feitas por indivíduos e empresas, cada qual agindo em termos de um conjunto de expectativas e preferências manifestadas nesses níveis (STIGLER, 1952). Não é necessário que os microprocessos envolvam escolha, por certo. O comportamento agregado em um grupo pode ser definido como a conseqüência do entrelaçamento de um aprendizado por tentativa e erro que ocorre no nível do indivíduo (LAVE \& MARCH, 1975). Ou o comportamento agregado de uma indústria pode ser definido como a conseqüência do entrelaçamento de procedimentos de operação-padrão e de normas contábeis seguidos no nível da firma individual (NELSON \& WINTER, 1982).

Não há nada de intrínseco em uma perspectiva que enfatiza as macroconseqüências de microações que requeira que as unidades elementares sejam individuais. Tudo o que se requer é que o comportamento de um sistema mais abrangente seja decomponível em comportamentos elementares explicáveis em um nível menos abrangente. Entretanto, na prática, na maior parte das Ciências Sociais, as ações de seres humanos individuais são consideradas como determinando o fluxo de eventos em um sistema social maior. Considerase que os resultados no nível do sistema são de- 
terminados pelas interações entre indivíduos que agem consistentemente em termos de axiomas do comportamento individual, quaisquer que eles sejam. Assim, fazemos suposições sobre consumidores individuais a fim de entender os mercados, sobre eleitores a fim de entender a política e sobre burocratas a fim de entender as burocracias.

As duas teorias do comportamento agregado mais bem especificadas, a teoria econômica dos mercados e a teoria ecológica da competição ambiental, exemplificam o estilo moderno. Considere-se a teoria dos mercados. Nessa teoria, encontramos consumidores individuais, cada qual buscando fazer aquisições pelos melhores preços possíveis de acordo com suas próprias preferências e alternativas, e produtores individuais, cada qual buscando tomar decisões relativas à produção e aos preços que resultem no melhor retorno possível de acordo com suas próprias preferências e alternativas. Supõe-se que o comportamento do mercado seja compreensível em função das tomadas de decisão desses atores individuais que, em conjunto, redundam nos fenômenos de mercado. Considere-se, de maneira similar, a teoria ecológica da competição ambiental. Nessa teoria, encontramos espécies individuais, cada qual se adaptando a um ambiente por meio da sobrevivência, da mutação e da reprodução. Supõe-se que a seleção e as mudanças na distribuição da população no ambiente sejam compreensíveis como consequiências das ações de atores individuais que, em combinação com as ações de outros e da capacidade potencial do ambiente, produzem uma distribuição de tipos.

II.3. A ação como a tomada de decisões calculadas: o utilitarismo

Historicamente, a Ciência Política enfatizou as maneiras em que o comportamento político esteve inserido em uma estrutura institucional de regras, normas, expectativas e tradições, as quais limitavam severamente o livre exercício da vontade e do cálculo individual (WOLIN, 1960). Por outro lado, na maior parte dos casos, a Ciência Política moderna descreveu os eventos políticos como a conseqüência de decisões calculadas. Não somente na Ciência Política, mas ao longo de toda a moderna obra teórica nas Ciências Sociais, a visão proeminente do comportamento humano é uma visão da escolha. A vida é caracterizada como sendo a tomada de decisões deliberadas.
Os detalhes a respeito da metáfora da escolha variam de uma abordagem para outra, mas a forma característica supõe que as escolhas originamse a partir de duas conjecturas sobre o futuro. A primeira é sobre as incertas conseqüências futuras da ação atual possível. Os teóricos da decisão reconhecem que as limitações humanas podem restringir a precisão das estimativas, que as estimativas podem ser parciais e que as informações em que as estimativas baseiam-se podem ser dispendiosas; mas as informações sobre as conseqüências prováveis são supostas como importantes para uma escolha. A partir dessa suposição, sucede uma ênfase no poder da informação e da competência (CROZIER, 1964) e na importância de fontes de informação confiáveis e imparciais (NISBET \& ROSS, 1980). Embora numerosos experimentos psicológicos tenham indicado que as conjecturas dos seres humanos são parciais (KAHNEMAN, SLOVIC \& TVERSKY, 1982), não foi fácil formular alternativas à noção simples de que as conjecturas dos seres humanos experientes são, na média, precisas. Como resultado disso, a maior parte das teorias da escolha apresentam as decisões como sendo, na média, sensatas. Em suas versões políticas, as teorias da escolha supõem que, na média, os eleitores votam com inteligência no que tange aos seus interesses; os legisladores organizam coalizões sensatas, dados os seus interesses, e estados-nação fazem alianças, voluntariamente, que, na média, melhoram suas posições.

A segunda conjectura sobre a qual a escolha intencional e antecipatória baseia-se é sobre as incertas preferências futuras do tomador de decisão por possíveis resultados futuros. Em qualquer teoria sobre a escolha deliberada, as ações dependem dos valores do tomador de decisão. Visto que as conseqüências de interesse devem ser obtidas no futuro, é necessário antecipar não somente o que acontecerá, mas como o tomador de decisão sentir-se-á a respeito daqueles resultados quando experimentados (MARCH, 1978). As complexidades desta segunda conjectura são largamente ignoradas por teorias da escolha. Em suas formas-padrão, essas teorias supõem que as preferências são estáveis e, em consequiência, que as preferências atuais são bons preditores de preferências futuras; que as preferências são consistentes e não são ambíguas, de tal sorte que uma escolha será claramente a indicada, dada a pri- 
meira conjectura; que as preferências são exógenas, de modo que, qualquer que seja o processo que gere as preferências, ele precede à escolha e é independente do processo de escolha. Em uma das mais bem desenvolvidas formas de uma teoria da escolha, essas suposições com respeito a preferências são tomadas como axiomas e as preferências são descobertas sem se pedir aos tomadores de decisão que as relatem, mas por meio da definição de uma função de "preferência revelada" que satisfaça os axiomas e seja consistente com as escolhas feitas pelo tomador de decisão (LUCE \& RAIFFA, 1957). Embora a existência empírica de preferências reveladas consistentes tenha sido objeto de debates consideráveis (BECKER \& STIGLER, 1977; KAHNEMAN, SLOVIC \& TVERSKY, 1982), a idéia teórica forma as bases do extenso desenvolvimento analítico e da exploração empírica.

\section{II.4. A eficiência da história: o funcionalismo}

Historicamente, a Teoria Política tem sido ambivalente sobre a eficiência da história. Os estudiosos do desenvolvimento político, assim como outros cientistas sociais, têm-se inclinado a aceitar uma idéia de progresso, o movimento histórico mais ou menos inexorável em direção a algum nível mais "avançado". Ao mesmo tempo, as histórias políticas freqüentemente enfatizaram a significância singular de uma seqüência particular de eventos ou escolhas, o impacto de uma estratégia ou discurso de campanha particular ou as táticas particulares da negociação internacional. No uso moderno, a terminologia do progresso foi largamente substituída por uma terminologia da sobrevivência, mas na Ciência Política teórica contemporânea, na maior parte dos casos considera-se que as instituições e o comportamento evoluem por meio de alguma forma de processo histórico eficiente.

Um processo histórico eficiente, nesses termos, é aquele que se move rapidamente para uma solução singular, dependente das condições ambientais do momento e, assim, independente da trajetória histórica. O equilíbrio pode envolver uma distribuição estocasticamente estável ou um ponto fixo, mas requer-se uma solução que seja alcançada com relativa rapidez e que seja independente dos detalhes dos eventos históricos que conduzem a ela. A suposição de eficiência histórica é uma suposição-padrão de muito da moderna Ciência Social, embora comumente não-explíci- ta. As teorias econômicas dos mercados e as teorias ecológicas da competição, por exemplo, estão preocupadas com as características de um equilíbrio, se é que ele existe. Elas são usadas para predizer diferenças (por exemplo, em mercados, em estruturas organizacionais, na população, em tecnologias) que serão observadas, em equilíbrio, em diferentes ambientes. De modo semelhante, algumas teorias dos partidos políticos do período posterior à II Guerra Mundial vêem a orientação e a organização partidárias como soluções de equilíbrio para problemas de sobrevivência em um ambiente político competitivo (DOWNS, 1957). A suposição de eficiência histórica faz que essas teorias sejam largamente indiferentes à realidade comportamental dos microprocessos que se supõem. Por exemplo, pode-se supor que a competição elimine a ação que seja inconsistente com a lógica da sobrevivência. Os exemplos incluem teorias do equilíbrio de mercado, tais como aquelas encontradas em idéias recentes a respeito de mercados de capitais eficientes (SHARPE, 1970); teorias das estruturas organizacionais, tais como aquelas encontradas em idéias recentes a respeito da organização industrial (WILLIAMSON, 1978), e teorias dos partidos políticos, tais como aquelas encontradas nas idéias da Economia Política (OLSON, 1965).

Não se pode garantir que a história seja eficiente. Um equilíbrio pode não existir. Mesmo se houver um equilíbrio, os processos históricos podem muito bem ser bastante lentos em relação à taxa de mudanças no ambiente, de modo que é improvável que o equilíbrio do processo seja alcançado antes das mudanças no ambiente e, assim, do equilíbrio. Ao suporem rapidez, as teorias do comportamento político evitam enfocar em fenômenos transitórios que podem ser menos previsíveis e mais sujeitos aos efeitos dos detalhes dos processos envolvidos. Por exemplo, quando se prediz que partidos políticos convergirão para posições idênticas em um ambiente de preferências de voto single-peaked ${ }^{4}$, supõe-se que o ajuste partidário será muito mais rápido do que o serão as mudanças de preferência de voto. A eficiência requer também que o equilíbrio seja singular e alcançável. Processos com múltiplos equilíbrios são, evidentemente, especificados com fa-

4 As preferências são consideradas single-peaked quando sua ordenação é determinada pela posição de uma política em relação à sua política preferida (N. T.). 
cilidade e freqüentemente observados. O que os torna pouco atraentes não é sua raridade, mas sua intratabilidade e a indeterminação de seus resultados. Não é por acaso que o princípio mais comum das teorias em Ciências Sociais é o princípio da otimização e que uma das maiores preocupações em tais teorias é mostrar que um processo possui um nível ótimo singular que será indubitavelmente alcançado.

\section{II.5. A primazia dos resultados: o instrumen- talismo}

Historicamente, as teorias das instituições políticas retrataram as tomadas de decisão políticas primordialmente como um processo com o fim de desenvolver um senso de propósito, direção, identidade e pertencimento. A política era um veículo para a educação dos cidadãos e o melhoramento dos valores culturais. Embora haja exceções, de modo geral a perspectiva moderna na Ciência Política deu primazia aos resultados e, ou ignorou as ações simbólicas, ou percebeu os símbolos como parte de esforços manipulativos com o fim de controlar os resultados, em vez do reverso disso.

Os modernos estados politicamente organizados são tão repletos de símbolos, rituais, cerimônias e mitos quanto as sociedades mais familiares à tradição antropológica. Os políticos anunciam apoio público a posições que são incapazes de defender em privado (EDELMAN, 1964). Os legisladores votam a favor de legislações ao mesmo tempo em que permanecem indiferentes quanto à sua implementação (PRESSMAN \& WILDAVSKY, 1973). Os administradores solicitam a participação pública na tomada de decisões a fim de assegurar apoio público às políticas com as quais já se encontram comprometidos. Os altos dirigentes defendem a reorganização da burocracia pública, anunciam planos para realizar essas reorganizações e, com regularidade, abandonam esses planos (MARCH \& OLSEN, 1983). Informações são coletadas, políticas alternativas definidas e análises de custo e benefício realizadas, mas elas parecem estar mais dirigidas a reassegurar os observadores da adequação das ações sendo tomadas do que influenciar as ações (FELDMAN \& MARCH, 1981).

Nas discussões modernas sobre política, essas ações simbólicas são caracteristicamente retratadas como movimentos estratégicos realizados por atores políticos autoconscientes. Rituais e cerimônias são definidos como fachadas para os processos políticos reais ou como instrumentos pelos quais os espertos e poderosos exploram os ingênuos e os fracos. A contratação de peritos empresta legitimidade a políticas (MEYER \& ROWAN, 1977); a associação de movimentos impopulares com símbolos populares é animador (EDELMAN, 1964). O controle de símbolos constitui-se em uma base de poder, assim como o controle sobre outros recursos (PFEFFER, 1981a), e o uso de símbolos é parte de uma luta pelos resultados políticos (COHEN, 1974).

\section{AS PERSPECTIVAS INSTITUCIONALIS-}

\section{TAS}

O neo-institucionalismo não é peculiar à Ciência Política. O renovado interesse nas instituições é característico de tendências recentes na Economia, que descobriu a lei, os contratos, as hierarquias, os procedimentos de operação-padrão, os códigos profissionais e as normas sociais (AKERLOF, 1980). Também é visto na Antropologia e na Sociologia, embora visões nãoinstitucionalistas nunca tenham sido bem-sucedidas nesses campos tanto quanto foram na Ciência Política e na Economia. Também não são inteiramente novas as idéias institucionalistas. Ao designar essa coleção de idéias de "neoinstitucionalismo", queremos fazer notar o fato de que houve, com efeito, um "velho institucionalismo", que ciclos no mundo das idéias trouxeram-nos de volta considerações que tipificaram formas anteriores de teoria na Ciência Política. Entretanto, não queremos sugerir que o novo e o velho sejam idênticos. Provavelmente, seria mais exato descrever o pensamento recente como combinando elementos de um velho institucionalismo aos estilos não-institucionalistas de recentes teorias da política.

Esse neo-institucionalismo pode ser apresentado e discutido como uma perspectiva epistemológica de profunda importância para entender-se as Ciências Sociais, mas, para nossos propósitos, é mais útil defini-lo em termos de uma coleção restrita de desafios ao pensamento teórico contemporâneo, um pequeno conjunto de idéias relativamente técnicas de primordial interesse para os estudiosos profissionais da vida política. Essas idéias minimizam a dependência do Estado politicamente organizado com relação à sociedade em favor de uma interdependência entre instituições sociais e políticas relativamente autôno- 
mas; elas minimizam a simples primazia de microprocessos e histórias eficientes em favor de processos relativamente complexos e da ineficiência histórica; elas minimizam as metáforas da escolha e os resultados alocativos em favor de outras lógicas de ação e da centralidade do significado e da ação simbólica. As idéias não são todas mutuamente consistentes. Com efeito, algumas delas parecem mutuamente inconsistentes. Por exemplo, idéias baseadas na suposição de que estruturas institucionais grandes (por exemplo, organizações, legislaturas, estados) podem ser retratadas como atores autônomos racionalmente coerentes são companheiras incômodas para idéias que sugerem que a ação política está inadequadamente descrita em termos de racionalidade e de escolha.

\section{III.1. A posição causal das instituições políticas}

Sem negar a importância tanto do contexto social da política quanto das motivações dos atores individuais, o neo-institucionalismo insiste em um papel mais autônomo para as instituições políticas. O Estado não é somente afetado pela sociedade, mas também a afeta (KATZENSTEIN, 1978; KRASNER, 1978; STEPHAN, 1978; SKOCPOL, 1979; NORDLINGER, 1981). A democracia política depende não somente da economia e das condições sociais, mas também do desenho das instituições políticas. A agência burocrática, a comissão legislativa e as cortes de apelação são arenas para as forças sociais contraditórias, mas também são uma coleção de procedimentos e estruturas de operação-padrão que definem e defendem interesses; elas são atores políticos em si.

$\mathrm{O}$ argumento de que as instituições podem ser tratadas como atores políticos constitui-se em uma reivindicação de coerência e de autonomia institucionais. A reivindicação de coerência é necessária a fim de tratar as instituições como tomadoras de decisão. De tal ponto de vista, a questão é se desejamos conceber o Estado (ou alguma outra instituição política) como fazendo escolhas com base em algum interesse ou intenção coletivos (por exemplo, preferências, objetivos, propósitos), alternativas e expectativas (LEVI, 1981). Não há resposta obrigatória para essa questão, a menos que imponhamos uma. Se faz sentido ou não, de um ponto de vista teóricopragmático, imputar interesses, expectativas e as outras parafernálias da inteligência coerente a uma instituição, $a$ priori não é algo nem mais nem menos problemático do que se faz sentido ou não as imputar a um indivíduo (KAHNEMAN, 1982; MARCH \& SHAPIRO, 1982). A resposta pragmática parece ser a de que a coerência das instituições varia, mas é, por vezes, substancial o bastante para justificar que se considere a coletividade como agindo coerentemente.

A reivindicação de autonomia é necessária para estabelecer que as instituições políticas são mais do que simples espelhos de forças sociais. As observações empíricas parecem indicar que os processos internos às instituições políticas, embora possivelmente iniciados por eventos externos, afetam o fluxo da história. Programas adotados como um simples acordo político por uma dada legislatura tornam-se dotados de um significado e de uma força distintos em virtude de possuírem uma agência que foi estabelecida para cuidar deles (SKOPCOL \& FINEGOLD, 1982). A implantação de políticas públicas ou a competição entre burocratas ou legisladores ativa e organiza as identidades e clivagens sociais de outro modo quiescentes (TILLY, 1978; OLSEN \& SAETREN, 1980). Dentro do sistema político, especialistas em políticas desenvolvem e conformam o entendimento das questões e das alternativas relacionadas a essas políticas (HEDO, 1974).

Tais fenômenos não são costumeiramente acomodados pela Teoria Política moderna, o que torna os resultados políticos uma função de três fatores primordiais: a distribuição de preferências (interesses) entre atores políticos, a distribuição de recursos (poderes) e os constrangimentos impostos pelas regras do jogo (constituições). Cada um desses é tratado como exógeno ao sistema político. Isto é, as preferências são desenvolvidas no interior de uma sociedade e transmitidas por meio da socialização; os recursos são distribuídos entre atores políticos por algum processo social amplo e as regras do jogo são ou estáveis, ou mudam por meio de uma intervenção revolucionária exógena às atividades políticas ordinárias.

A idéia de que as preferências são produzidas e alteradas por um processo exógeno aos processos de escolha é fundamental para a teoria da decisão moderna. Na versão da teoria da "preferência revelada”, para que a teoria seja testável as preferências devem ser estáveis. Em outras versões, as preferências podem mudar, mas a escolha em si não produz mudança de preferências. As teorias convencionais dos mercados, por exem- 
plo, concebem a publicidade e a experiência como fornecendo informações sobre alternativas e suas propriedades, não como afetando gostos. De modo semelhante, as teorias convencionais da política supõem que a exposição do eleitor a um candidato e sua escolha por um não alteram suas preferências quanto aos vários atributos que um candidato possa ter, embora elas possam mudar as crenças dos eleitores a respeito de quais candidatos têm quais atributos. O neo-institucionalismo, juntamente com a maior parte das pesquisas sobre preferências, argumenta que na política, assim como no restante da vida, as preferências e os significados desenvolvem-se por meio de uma combinação de educação, doutrinamento e experiência. Eles não são nem estáveis nem exógenos (COHEN \& AXELROD, 1984). Se as preferências políticas são moldadas por meio de experiências políticas ou por instituições políticas, é canhestro ter-se uma teoria que suponha que as preferências sejam exógenas ao processo político. E se as preferências não são exógenas ao processo político, é incômodo conceber o sistema político como estritamente dependente da sociedade a ele associada.

O contraste entre os dois tipos de noções é encontrado mais nitidamente em teorias da liderança política. Uma idéia clássica de liderança política enfatiza a criação de coalizões políticas vencedoras entre participantes com certas demandas (MARCH, 1970). O papel da liderança é o de um intermediário: fornecer informações, identificar coalizões possíveis e facilitar o intercâmbio de concessões [side-payments] e a articulação de trocas de favores. Tal visão de liderança está implícita na teoria do processo político que foi desenvolvida na Ciência Política em décadas recentes. Uma segunda concepção de liderança enfatiza a transformação das preferências, tanto aquelas do líder quanto aquelas dos seguidores (SELZNICK, 1957; BURNS, 1978). Os líderes interagem com outros líderes e são cooptados para assumir novos compromissos e crenças. O papel da liderança é aquele de um educador, estimulando e aderindo a visões de mundo em mutação, redefinindo significados e estimulando compromissos. Tal visão é mais conspícua nas idéias do neoinstitucionalismo.

A distribuição dos recursos políticos também é parcialmente determinada de maneira endógena. As instituições políticas afetam a distribuição dos recursos, o que por sua vez afeta o poder dos atores políticos, afetando, conseqüentemente, as instituições políticas. Riqueza, posição social, reputação de poder, conhecimento de alternativas e atenção não são coisas facilmente descritas como exógenas ao processo político e às instituições políticas. A ocupação de um cargo no Estado provê direitos de participação e altera a distribuição de poder e de acesso (LAEGREID \& OLSEN, 1978; EGEBERG, 1981). As políticas alternativas dos líderes não são completamente definidas por forças exógenas, mas são modeladas por agências administrativas existentes (SKOCPOL, 1980; SKOCPOL \& FINEGOLD, 1982; SKOWRONEK, 1982). Os resultados do processo político modificam as reputações de poder, as quais, por sua vez, modificam os resultados políticos (MARCH, 1966; ENDERUD, 1976).

Por fim, o terceiro fator exógeno em teorias convencionais da política - as regras do jogo também não é realmente exógeno. As constituições, as leis, os contratos e as regras usuais da política tornam muitas ações ou considerações potenciais, ilegítimas ou não-observadas; algumas alternativas são excluídas da agenda antes que a política inicie-se (BACHRACH \& BARATZ, 1962), mas esses constrangimentos não são impostos de modo completo por um sistema social externo; eles desenvolvem-se no contexto das instituições políticas. As agências públicas criam regras e fazem que os políticos sancionem-nas (ECKHOFF \& JACOBSEN, 1960) e as mudanças revolucionárias são iniciadas e perseguidas por burocratas militares (TRIMBERGER, 1978).

\section{III.2. A complexidade causal da história política}

As teorias políticas tendem a supor a existência de um entrelaçamento relativamente descomplicado entre as unidades elementares de um sistema político. Pode haver muitos indivíduos, grupos ou classes envolvidos, mas eles são relativamente indiferenciados e suas ações são relativamente simples. Por outro lado, as observações empíricas de sistemas políticos freqüentemente salientam a complexidade institucional dos estados modernos (ASHFORD, 1977; SCHARPF, 1977) e identificam um enlaçamento bastante complexo entre instituições, indivíduos e eventos. As alternativas não são fornecidas automaticamente a um tomador de decisão: elas devem ser encontradas. A busca de alternativas ocorre em um contexto organizado 
em que os problemas não somente procuram soluções, mas as soluções procuram problemas. As informações sobre as conseqüências das alternativas são geradas e comunicadas por meio de instituições organizadas, de modo que as expectativas dependem da estrutura de conexões dentro do sistema, assim como as maneiras pelas quais os vieses e contra-vieses acumulam-se (SIMON, 1957a; 1957b). As conjecturas sobre as preferências futuras desenvolvem-se dentro de instituições dedicadas a definir e modificar valores e os significados das ações (CYERT \& MARCH, 1963; MARCH \& OLSEN, 1976). Há muitas dessas instituições, algumas aninhadas dentro de outras, com conexões múltiplas e imbricadas (LONG, 1958). Sistemas políticos nacionais encaixam-se em sistemas políticos internacionais e são compostos de numerosos subsistemas, alguns dos quais se estendem para além das fronteiras nacionais.

Se essa complexidade não pode ser decomposta analiticamente em partes menores ou não é suscetível à aplicação de certas técnicas de agregação relativamente simples, os problemas teóricos relacionados ao entendimento da história social não são facilmente acomodados no interior dos estilos teóricos contemporâneos. Por exemplo, pode ser temerário supor que erros relacionados a expectativas possuam uma distribuição normal com uma média zero. A alocação de atenção pode ser crítica para o fluxo dos eventos. A responsividade do sistema político a pressões ambientais pode, ao menos no curto prazo, depender do montante de inatividade no sistema e das maneiras pelas quais os números contábeis [accounting numbers] são produzidos e postos de lado. O sistema pode não chegar perto de tentar resolver conflitos, mas pode, simplesmente, atender, em seqüência, as demandas dele exigidas (CYERT \& MARCH, 1963). O aprendizado pode ser supersticioso e regras de inferência falaciosas podem persistir por longos períodos (NISBET \& ROSS, 1980). No limite, as conexões entre problemas e soluções podem ser menos dominadas por uma lógica de conexões causais entre meios e fins do que pelas menos problemáticas conexões temporais de simultaneidade (COHEN, MARCH \& OLSEN, 1972).

Mais comumente, as teorias do comportamento coletivo simplificam o potencial atoleiro da complexidade coletiva por uma de duas vias clássicas. A primeira é a da agregação estatística. Em seu aspecto usual, a agregação supõe que os fatores afetando os resultados podem ser divididos em dois grupos, um sistemático e outro aleatório. Assim, por exemplo, poderíamos supor que em uma população de eleitores existem muitos fatores afetando a escolha eleitoral. Alguns desses fatores (por exemplo, a renda) têm impactos no voto que são fortes e consistentes ao longo de todo o espectro de indivíduos. Outros fatores (por exemplo, questões a respeito de políticas específicas) têm impactos que são mais fracos ou menos consistentes ou menos bem entendidos. Se supusermos que estes últimos fatores podem ser tratados como ruídos, isto é, que são variáveis independentes, distribuídas aleatoriamente, os fatores sistemáticos ficarão claros nos resultados agregados. Dessa maneira, suposições convencionais de agregação impõem uma ordem estatística aos resultados.

A segunda simplificação clássica é a suposição de eficiência histórica. Embora esse argumento esteja comumente associado a teorias da seleção natural e melhor especificado em teorias modernas de Biologia de Populações, a idéia básica da eficiência histórica está implícita em muitas teorias modernas. Independentemente da complexidade ou das aparentes anomalias do comportamento humano, supõe-se que os processos históricos eliminam regras de comportamento que não são soluções para um problema de adequada otimização conjunta. Assim, uma predição baseada na solução do problema de otimização predirá comportamentos corretamente, independentemente de se os atores envolvidos formulam ou resolvem esse problema explicitamente (FRIEDMAN, 1953). Por exemplo, poderíamos predizer o resultado de uma complexa negociação política por meio da suposição de que os atores envolvidos estejam, cada um deles, agindo racionalmente com base em informações integrais a respeito um do outro e do mundo, apesar de que reconheçamos que tais suposições são inteiramente falsas como uma descrição do comportamento individual.

Os estudiosos das instituições sugerem simplificações teóricas alternativas para entenderem sistemas políticos complexos, mais comumente a suposição de uma estrutura política. Por "estrutura política” queremos dizer um conjunto de instituições, regras de comportamento, normas, papéis, arranjos materiais, edificações e arquivos que são relativamente invariantes frente à rotatividade 
de indivíduos e relativamente resilientes às preferências e expectativas idiossincráticas dos indivíduos. Em contraste com teorias que supõem que a ação constitui-se em escolha baseada nos valores de indivíduos, as teorias da estrutura política supõem que a ação constitui-se no cumprimento de deveres e de obrigações. A diferença é importante. Em uma metáfora da escolha, supomos que os atores políticos consultam preferências pessoais e expectativas subjetivas; em seguida, que selecionam ações que são tão consistentes quanto possível com aquelas preferências e expectativas. Em uma metáfora do dever, supomos que os atores políticos associam certas ações com certas situações por meio de regras de adequação. O que é adequado para uma pessoa particular em uma situação particular é definido pelo sistema político e social e transmitido por meio da socialização.

A estrutura política simplifica o mundo complexo para os indivíduos que nela estão. Entretanto, ela não torna os problemas do teórico político necessariamente mais simples. $\mathrm{O}$ complexo entrelaçamento de comportamentos guiados pelas regras pode ser tão difícil de desemaranhar quanto o complexo entrelaçamento de comportamentos guiados por preferências. Como resultado disso, existe, desde muito, uma tendência de combinar-se idéias de estrutura política com idéias de eficiência histórica. Se o comportamento individual no interior de uma estrutura política é guiado pelas regras, então é possível imaginar que a experiência histórica acumula-se ao longo de gerações de experiências individuais. A informação sobre aquelas experiências encontra-se codificada nas regras institucionais (NELSON \& WINTER, 1982). Esse argumento é familiar ao discurso político. Ele foi parte da doutrina conservadora por centenas de anos, formando uma base para a defesa tanto das regras de comportamento tradicionais quanto da ordem política existente.

Para além de sua aparente consistência com numerosas observações, a vantagem de tratar o comportamento como algo guiado pelas regras não é que é possível, desse modo, "salvar" a crença na eficiência histórica; mais exatamente, é que isso conduz - de modo mais natural do que tratar o comportamento como uma otimização - a um exame das maneiras específicas nas quais a história encontra-se codificada em regras e, desse modo, torna a idéia de eficiência histórica mais atenta às possíveis condições limitativas de efici- ência e mais suscetíveis de gerar predições interessantes a respeito de equilíbrios múltiplos ou longas trajetórias temporais. De fato, a suposição de eficiência torna-se principalmente uma questão de fé se o problema de otimização associado não puder ser especificado ou resolvido pelo observador ou se for impossível identificar os mecanismos precisos pelos quais a experiência histórica é transformada em ação no tempo presente. A menos que o processo seja especificado, é impossível examinar quer a probabilidade de que um equilíbrio particular será alcançado, quer quanto tempo levar-se-á para isso.

\section{III.3. A política como uma interpretação da vida}

Uma concepção de política como tomada de decisões é pelo menos tão antiga quanto Platão e Aristóteles. Ela reflete-se na linguagem e nas preocupações do pensamento político, desde os primeiros filósofos políticos, passando por Bentham até Merriam e Lasswell. Quem consegue e como? Na maior parte dos casos, a teoria contemporânea da Ciência Política considera a política e o comportamento político nesses termos instrumentais. O intento das ações encontra-se em seus resultados e o princípio organizador de um sistema político é a alocação de recursos escassos frente a conflitos de interesse. Assim, ação é escolha; escolhas são feitas em termos de expectativas quanto a suas conseqüências; significados são organizados para afetarem as escolhas; símbolos são cortinas que obscurecem a política real ou artefatos de um esforço para tomar-se decisões.

Partes do neo-institucionalismo são desafios a essa primazia dos resultados. Esses desafios ecoam um outro tema antigo do pensamento político: a idéia de que a política cria e confirma interpretações da vida. Por meio da política, os indivíduos desenvolvem-se, assim como suas comunidades e o bem público. Nessa visão, a participação na vida cívica é a forma mais elevada de atividade de uma pessoa civilizada. Essas idéias encontram vozes pós-helenísticas em J. S. Mill, Pateman (1970) e Lafferty (1981). A política é considerada como educação, como um lugar para descobrir, elaborar e expressar significados, estabelecer concepções compartilhadas (ou opostas) de experiência, de valores e a natureza da existência. É simbólica, não no sentido recente de símbolos como artifícios dos poderosos para confundir os fracos, porém mais no sentido de símbolos como instrumentos de ordem interpretativa. 
A fonte primordial do desafio institucionalista é empírica. Os observadores dos processos de tomada de decisão discernem com regularidade características difíceis de serem relacionadas com uma concepção de escolha coletiva orientada para o resultado. A satisfação está freqüentemente no processo. Os participantes potenciais parecem importar-se com o direito de participação tanto quanto com o fato da participação; os participantes recordam-se das características do processo mais fácil e vividamente do que de seus resultados; argumentos acalorados conduzem a decisões sem que haja preocupações sobre sua implementação; informações relevantes para uma decisão são solicitadas, mas não são consideradas; a autoridade é exigida, mas não é exercida (MARCH \& OLSEN, 1976; FELDMAN \& MARCH, 1981). Essas observações são freqüentemente relatadas como anomalias, como sintomas de algum tipo de perversidade nos sistemas observados, paradoxais. Entretanto, a aparência de paradoxo é um produto de nossa pressuposição teórica de que o ponto central de um processo de tomada de decisões é a decisão. Para muitos propósitos, essa pressuposição pode ser enganadora. Os processos da política podem ser mais centrais do que seus resultados.

A política e a governança são rituais sociais importantes. Em mundos idos, em que a força causal mais importante que produzia a experiência histórica era a vontade dos deuses, os rituais sociais eram organizados em torno de cerimônias pelas quais essa vontade era descoberta e influenciada. Sociedades contemporâneas mais desenvolvidas, de algum modo mais seculares em suas concepções de causalidade, acreditam que a experiência é produzida por uma combinação de leis naturais e ação humana intencional. Portanto, nessas sociedades, os rituais sociais e políticos são organizados em torno da consulta aos especialistas e da tomada de decisões (OLSEN, 1970). Os procedimentos de decisão que observamos são reflexos e lembretes dessa concepção moderna e secular da ordem social. Elas são sinais e símbolos da adequação dos eventos, não no sentido de que o que aconteceu necessita ser visto como desejável ou agradável, mas no sentido de que o que aconteceu pode ser visto como tendo ocorrido da maneira que as coisas acontecem (FELDMAN \& MARCH, 1981). O termo usual é "legítimo"; mas a legitimidade pode denotar alguma coisa mais restrita do que se intente, pois o que os rituais procuram estabelecer é não somente a virtude moral dos eventos, mas também sua necessidade.

\section{A PESQUISA TEÓRICA E AS INSTITUI- ÇÕES POLÍTICAS}

As ações humanas, os contextos sociais e as instituições operam uns sobre os outros de maneiras complexas; esses processos de ação complexos e interativos e a formação de significados são importantes para a vida política. As instituições não parecem ser nem reflexos neutros de forças ambientais exógenas nem arenas neutras para o desempenho de indivíduos guiados por preferências e expectativas exógenas. Como resultado disso, a Teoria Política contemporânea é provavelmente confiante em demasia a respeito da possibilidade de uma teoria da política que ignore as instituições políticas.

Entretanto, na maioria dos casos, o trabalho teórico relevante ainda está por ser feito. A sugestão de que as instituições políticas e a sociedade são independentes é interessante, mas essa afirmação precisa encontrar uma expressão teórica mais rica. É adequado observar que as instituições políticas podem ser tratadas como atores quase da mesma maneira pela qual tratamos os indivíduos como tais; mas carecemos de demonstrações mais detalhadas da utilidade de fazer-se isso. É de bom senso notar que a história não é necessariamente eficiente, mas seria de uma ajuda ainda maior se fôssemos capazes de mostrar as maneiras específicas pelas quais processos específicos dependentes da história conduzem a resultados que são ou não-singulares ou muito atrasados sob algumas condições. É plausível argumentar que a política está repleta de comportamentos que são difíceis de encaixar em um modelo utilitário; mas a plausibilidade aumentaria se conseguíssemos descrever um modelo alternativo. E é provocativo notar a importância dos símbolos, rituais, cerimônias e mitos na vida política, mas não podemos sustentar essa provocação sem uma especificação mais clara de como as teorias políticas são afetadas por tal visão.

Mover-se de julgamentos sutis sobre o conhecimento empírico em direção a uma formulação teórica adequada não é mais fácil na análise da política do que seria em outra atividade. Isso requer não somente estudos empíricos mais extensos, mas, também, pesquisa teórica. Por pesqui- 
sa teórica queremos dizer, primordialmente, o desenvolvimento de idéias, conceitos e modelos baseados em observações empíricas, relevantes para um entendimento comportamental e uma ordenação prescritiva da vida política. Esse objetivo não é impossível de ser atingido. Trinta anos atrás, os estudiosos das organizações de orientação empírica fizeram duas grandes críticas à existente teoria organizacional da tomada de decisões. A primeira crítica foi a de que a teoria fez extraordinárias demandas de tempo e de informação às organizações (SIMON, 1957a; 1957b; MARCH \& SIMON, 1958). A informação e o tempo foram tratados como recursos livremente disponíveis. Requerer que todas as conseqüências de todas as alternativas fossem conhecidas de modo preciso parecia irrazoável frente à evidência empírica de que as organizações consideravam somente um pequeno número de alternativas, examinavam somente um pequeno número de conseqüências relacionadas somente a um subconjunto de objetivos organizacionais e produziam estimativas relativamente imprecisas.

A segunda crítica foi a de que a teoria supôs que todos os participantes em uma organização compartilhavam os mesmos objetivos ou, se assim não fosse, que os conflitos entre eles podiam ser gerenciados prontamente conforme os termos de algum acordo prévio (MARCH, 1962; CYERT \& MARCH, 1963). No caso de uma organização política, o acordo era um contrato de coalizão, ou uma constituição, pelo qual todos os membros da coalizão ou do Estado politicamente organizado concordavam em sujeitar-se às políticas especificadas por meio de barganha ou da legislação. Daí a familiar distinção entre "política” e "administração”. No caso de uma organização econômica, o acordo era um contrato de trabalho pelo qual os empregados, em troca do pagamento de salário, concordavam em agir como se tivessem os mesmos objetivos que o dono ou que outro formulador de políticas legítimo. Estudos empíricos pareceram indicar que o conflito nas organizações era endêmico e que ele tendia a ser interminável, em vez de resolver-se por meio dos acordos prévios. Essas críticas começaram a ter um sério impacto nas teorias formais da ação organizada no momento em que elas foram traduzidas em afirmações teóricas úteis por meio do desenvolvimento da economia da informação e das teorias da agência. Tais teorias consideram a informação como um recurso escasso sujeito à ação estratégica em um mundo povoado por atores racionais auto-interessados. As idéias extraídas dos estudos organizacionais sobre a racionalidade limitada e o conflito interno permeiam a teoria econômica moderna na forma de discussões sobre risco moral, informações assimétricas, agência, sinalização e estratégias ótimas de informação (HIRSHLEIFER \& RILEY, 1979). A maioria dos estudiosos das organizações argumentaria que essas teorias também são incompletas, mas está claro que as críticas empíricas anteriores reformaram a reflexão teórica.

O neo-institucionalismo beneficiar-se-ia de um desenvolvimento teórico similar se ele pudesse realizar-se. Assim como as observações anteriores sobre a racionalidade limitada e o conflito interno, as observações a respeito da importância das instituições tomaram, de modo geral, a forma de crítica das idéias teóricas existentes, em vez da delineação de um conjunto alternativo de conceitos teóricos precisos. Desenvolver uma estrutura teórica abrangente para a reflexão institucional é, por certo, uma tarefa prodigiosa e pretensiosa e não será empreendida aqui. Entretanto, podemos identificar algumas idéias associadas ao neoinstitucionalismo que poderiam ser merecedoras de atenção teórica.

\section{IV.1. Concepções institucionais de ordem}

A reflexão institucional enfatiza o papel desempenhado por estruturas institucionais na imposição de elementos de ordem em um mundo potencialmente imperfeito. A Teoria Política tradicional conferiu uma atenção considerável à ordem produzida pelos contratos políticos, refletida em constituições, leis e outras regras estáveis, ou por uma comunidade de obrigações morais, freqüentemente inspiradas e amparadas pelo dogma religioso (WATERSTONE, 1966; BERKI, 1979). Na maior parte dos casos, a Teoria Política contemporânea afasta-se de tais preocupações e concentrase na agregação e na eficiência histórica superpostas a dois outros tipos de ordem: a ordem imposta pela razão e a ordem imposta pela competição e pela coerção. Reconhece-se a razão nas idéias de racionalidade e de ação intencional; ela encontra expressão institucional na organização hierárquica de meios e fins (e, desse modo, em instituições planejadas formalmente). A competição e a coerção são reconhecidas em idéias de conflito de interesse, poder, barganha, sobrevivência e guerra; elas encontram expressão 
institucional nas eleições e na elaboração de políticas. A pesquisa teórica relevante para o neoinstitucionalismo envolveria a elaboração de noções adicionais de ordem política. Acreditamos ser possível identificar ao menos seis concepções desse tipo sobre as quais um montante modesto de trabalho teórico poderia gerar recompensas.

1) Ordem histórica. O conceito de ordem histórica implícito na teoria contemporânea enfatiza a eficiência dos processos históricos, as maneiras pelas quais a história move-se, rápida e inexoravelmente, na direção de um resultado singular, o qual é, normalmente e em um certo sentido, um nível ótimo. Uma teoria institucional especificaria como os processos históricos são afetados pelas características específicas de instituições políticas e proveria um entendimento teórico mais amplo quanto às ineficiências da história, isto é, processos históricos que não possuem equilíbrios, que ocorrem por longos períodos de tempo, que conduzem a equilíbrios não-singulares ou que têm resultados singulares, porém menos favoráveis. A atenção teórica com as ineficiências da história envolve uma preocupação maior com as maneiras pelas quais as instituições aprendem a partir de suas experiências (ETHEREDGE, 1976) e com as possibilidades de que o aprendizado produzirá ajustes mais lentos ou mais rápidos em relação ao adequado ou até mal-orientados. Ela envolve tentar especificar as condições sob as quais os ramos seqüenciais da história voltam-se uns sobre os outros e as condições sob as quais eles divergem; ela envolve caracterizar o papel dos procedimentos de operação-padrão, das profissões e da perícia em armazenar e recordar a história.

2) Ordem temporal. Na maioria das teorias da ação, supomos que as coisas estão ordenadas de acordo com suas conexões conseqüentes. Os meios estão conectados aos fins adequados; as causas estão conectadas aos efeitos que produzem; as conseqüências estão conectadas às ações que conduzem a elas e às preferências que afetam; as soluções estão conectadas aos problemas que resolvem. Tais conceitos de ordem constituem a base das teorias da escolha. Os desvios da ordem conseqüente são vistos como aberrações interessantes, distúrbios de um sistema de outro modo mantido unido pela maneira como o desejo por algo conduz à feitura de alguma coisa conectada àquele desejo e pela maneira como a feitura de alguma coisa conduz a conseqüências relacionadas à intenção. A ordem temporal provê uma alternativa em que as conexões são menos conseqüentes do que temporais. As coisas são conectadas em virtude de suas presenças ou chegadas simultâneas. Em uma cultura com um forte sentido de ciclos mensais ou anuais ou de coortes de nascimento, não deveríamos ficar demasiado surpresos pela ordem temporal. Em muitas situações envolvendo os seres humanos, a propriedade mais facilmente identificada de objetos ou de eventos são os subscritos temporais associados a eles. Por conseguinte, os estudiosos da alocação de tempo nas organizações observaram as maneiras por que a atenção a problemas parece ser determinada tanto pelo tempo de seu surgimento quanto por avaliações a respeito de sua importância. Uma forma clássica de ordem temporal é encontrada na teoria das filas, embora a maioria das discussões sobre filas esteja incluída em uma estrutura conseqüente na qual as filas são ou indistinguíveis ou distinguíveis somente por meio de seus tempos de processamento.

3) Ordem endógena. Uma boa parte da teoria contemporânea enfatiza a maneira pela qual a ordem é imposta sobre as instituições políticas por um ambiente externo. Dessa perspectiva, por exemplo, o poder dentro de um sistema político é determinado pela posse de recursos no ambiente, os interesses são determinados pela posição no mundo externo e a coerência no interior de uma instituição é assegurada pelas exigências da existência. Desse modo, a ordem é efetivamente exógena à instituição e não depende das suas propriedades ou dos processos em seu interior. Os estudiosos das instituições sugeriram diversas maneiras pelas quais os processos institucionais internos afetam coisas tais como a distribuição de poder, a distribuição de preferências ou a gestão do controle. Desse modo, eles convidam ao desenvolvimento teórico de modelos que sejam adequados para entender-se as ma- 
neiras pelas quais os interesses e as preferências desenvolvem-se no contexto da ação institucional, as maneiras por que as reputações de poder evoluem como conseqüência dos resultados da política, as maneiras pelas quais o processo de controle de organizações com determinados propósitos produz conseqüiências não-antecipadas e as maneiras por que o curso da tomada de decisões nos sistemas políticos, de modo sistemático e endógeno, resulta em ilusões de sucesso e de fracasso.

4) Ordem normativa. Na Ciência Social empírica, a observação de que o comportamento é constrangido e ditado pelos ditos culturais e normas sociais é um lugar-comum. Embora o interesse pessoal indubitavelmente permeie a política, a ação é freqüentemente mais baseada na descoberta dos comportamentos normativamente adequados do que no cálculo do retorno esperado a partir de escolhas alternativas. Como resultado disso, o comportamento político, assim como outros comportamentos, pode ser descrito em termos de deveres, obrigações, papéis e regras. Entretanto, tal descrição não foi traduzida em nenhuma forma teórica convincente. Alguns esforços foram feitos a fim de racionalizar regras normativas, como o altruísmo (KURZ, 1978) e a reciprocidade (AXELROD, 1980), ou de especificar as condições para sua evolução (TRIVERS, 1971; AXELROD \& HAMILTON, 1981). De uma perspectiva institucionalista, tais esforços são exemplares, mas eles tendem a limitar a atenção à estática comparativa das normas individuais. Um exame teórico mais abrangente da ordem normativa consideraria as relações entre as normas, a significância da ambigüidade e da inconsistência nas normas e a trajetória temporal da transformação de estruturas normativas. Um entendimento teórico de tais normas convencionais, como aquelas que circundam a confiança e a legitimidade, parece suscetível de ser particularmente pertinente para a análise política.

5) Ordem demográfica. É tentador para os estudiosos da política, assim como para os estudiosos de outros empreendimentos hu- manos, encontrar ordem, definida em termos da lógica de seu domínio particular de interesse. Desse modo, os estudiosos de legislaturas imaginam que uma legislatura é melhor entendida em termos da legiferação e os estudiosos das cortes imaginam que uma corte é melhor entendida em termos da tomada de decisões judiciais. Por outro lado, uma instituição humana pode ser estudada e interpretada como o corte transversal das vidas das pessoas envolvidas. A idéia de que o comportamento coletivo pode ser entendido como um mosaico de vidas privadas conecta o pensamento teórico contemporâneo a idéias similares difundidas entre estudiosos qualitativos do comportamento humano e romancistas (KRIEGER, 1983). O foco na demografia institucional combina tal visão de vida organizada com a atenção a uma propriedade das vidas individuais que é, ela mesma, um produto da estrutura institucional - a carreira individual (MARCH \& MARCH, 1978; PFEFFER, 1981b). Os requisitos teóricos incluem conceitos úteis a respeito das maneiras pelas quais as organizações adaptam-se à rotatividade; as instituições são guiadas por suas estruturas de coortes e a persecução de carreiras e padrões profissionais dita o fluxo dos eventos.

6) Ordem simbólica. Os estudiosos das organizações formais chamaram a atenção para a força ordenadora dos símbolos, dos rituais, das cerimônias, das histórias e do drama na vida política (MARCH \& OLSEN, 1976; 1983; MEYER \& ROWAN, 1977; PONDY, 1978; MARCH, 1981; PFEFFER, 1981a). Os símbolos permeiam a política de uma forma sutil e difusa, provendo coerência interpretativa para a vida política. Muitas das atividades e experiências da política são definidas por suas relações com os mitos e os símbolos que as precedem e que são amplamente compartilhados. Ao mesmo tempo, o comportamento simbólico também é um elemento estratégico na competição política. Indivíduos e grupos são freqüentemente hipócritas, recitando mitos sagrados sem acreditar neles ao mesmo tempo em que violam suas implicações. $\mathrm{O}$ problema tradicional com tais observações não é o da dúvida sobre sua veracidade, 
mas sobre nossa habilidade em traduzi-las em afirmações teóricas úteis sem que se cause um dano excessivo aos seus significados. O desenvolvimento teórico que seja o reflexo de uma perspectiva institucional incluiria um exame das maneiras pelas quais as tendências para consistência e inconsistência nas crenças afetam a organização do significado político, as maneiras pelas quais "centros exemplares" (GEERTZ, 1980) criam ordem social por meio de cerimônias e as maneiras pelas quais o comportamento simbólico transforma mais do comportamento instrumental e é transformado por ele. Em particular, um sério entendimento teórico de mitos, símbolos e rituais deve incluir alguma atenção à dinâmica dos símbolos e aos processos pelos quais os símbolos moldam o comportamento não somente dos ingênuos, mas da sociedade como um todo.

\section{IV.2. Exemplos de pesquisas teóricas possíveis}

No bojo dessas seis concepções de ordem, existem algumas possibilidades de pesquisas teóricas que atentam para os insights dos estudiosos das instituições. Tais pesquisas são institucionais em dois respeitos: em primeiro lugar, são orientadas por uma ou mais das concepções de ordem institucionalistas; em segundo lugar, tentam iluminar como os fatores institucionais e organizacionais afetam os eventos políticos. A título de exemplos, considere-se o seguinte.

Exemplo 1: policy martingales ${ }^{5}$. Muitos modelos da história reconhecem que eventos históricos específicos envolvem elementos relacionados ao acaso. $\mathrm{O}$ acontecimento histórico singular pode ser o resultado casual de alguma distribuição probabilística de eventos possíveis. Mesmo em situações em que o acaso, estritamente considerado, não é visto como vital, qualquer evento específico é visto como a conseqüência de um complexo entrelaçamento de fatores que são impossíveis de ser preditos com precisão em um único caso. Na versão de teste independente de tais modelos, qualquer evento histórico específico está sujeito a vários tipos de flutuações aleatórias, mas,

\footnotetext{
5 Essa expressão, que se mantém no original em inglês, é de difícil tradução; de qualquer forma, os autores explicam o seu sentido na seqüência (nota do revisor da tradução).
}

no longo prazo, eventos improváveis que ocorram em um momento particular são contrabalançados por eventos improváveis diferentes em um momento subseqüente. As realizações específicas do processo histórico que abrangem os eventos do presente são independentes das realizações específicas que abrangem os eventos do passado. Cada evento específico de uma história em desdobramento é relativamente difícil de predizer, mas a predição não é melhorada pelo conhecimento da história das realizações passadas daquele processo.

É possível compreender a elaboração de políticas como um processo de teste independente. Suponha-se que pensemos as políticas [policy] como a conseqüência da barganha entre atores políticos com preferências e recursos prévios, mas sujeitos a variações caso a caso atribuíveis a fatores específicos, imprevisíveis e incontroláveis. Entender a partir daí os resultados de curto prazo de um processo relacionado a uma política dependeria de detalhes consideráveis acerca da situação específica. Um estudioso das instituições poderia muito bem observar que os detalhes a respeito da maneira pela qual a atenção é organizada, como as alternativas são apresentadas, quais informações estão disponíveis, quais participantes estão livres de outras demandas, como a memória institucional é consultada e uma grande quantidade de outros fatores afetariam a política [policy] de cunho político [political] específica adotada em um momento específico. Ao mesmo tempo, entretanto, tais fatores são irrelevantes (ou redundantes) para entender-se a combinação de políticas de longo prazo. Um tal entendimento é possível simplesmente a partir do conhecimento do processo político subjacente e de quaisquer vieses institucionais sistemáticos.

Nem todos os processos de elaboração de políticas são processos de teste independentes. Muitos deles parecem ser mais da natureza dos martingales (FELLER, 1950). Assim como um processo de teste independente, um processo de martingale está sujeito à variação do acaso, mas as variações acumulam-se. O que distingue um martingale é a propriedade de que o valor que se espera do processo em um dado momento é igual ao da realização do processo em um momento anterior. Essa propriedade torna a trajetória específica da história importante para entender-se os eventos históricos atuais. Na verdade, as flutuações da história que ocorrem ao acaso alteram os pon- 
tos de partida do próximo passo do processo histórico. Descrições corriqueiras de processos incrementais relacionados a políticas fazem-nos parecer-se com a natureza dos martingales. A distribuição de resultados possíveis a partir de um processo relacionado a alguma política é concebida como conseqüência da competição e da barganha acerca de ajustes incrementais na política em curso; a política efetivamente adotada é um resultado casual que se dá a partir dessa distribuição. Essa propriedade de martingale da elaboração de políticas não é independente de fatores institucionais. Com efeito, parece ser uma característica institucional prototípica. As políticas, uma vez adotadas, ficam inseridas nas instituições. Elas associam-se a regras, expectativas e compromissos. Ao afetar a atenção e as aspirações, elas afetam o futuro comportamento de busca dos participantes políticos.

Os martingales divergem mais rapidamente do que os processos de teste independentes; isto é, para um dado montante de variação ao acaso em cada período de tempo, a variância entre resultados possíveis, após um certo número de períodos, será substancialmente maior em um martingale. Como resultado disso, a precisão com que realizações específicas do processo podem ser antecipadas é consideravelmente menor. Desse modo, martingales relacionados a políticas vinculam-se, porém não de maneira idêntica, a várias idéias menos precisas de bifurcações na história, de eventos críticos que fizeram a diferença. Em certo sentido, o primeiro passo é mais importante do que qualquer passo subseqüente; porém, esse é um sentido limitado. Em um processo de martingale, todos os eventos são bifurcações; as trajetórias de políticas de dois sistemas políticos com condições políticas subjacentes idênticas serão radicalmente diferentes simplesmente devido à maneira pelas quais as perturbações (possivelmente menores) alteram o foco da pressão política.

Exemplo 2: aprendizado empírico. A observação de que as instituições acumulam uma experiência histórica por meio do aprendizado é freqüente no institucionalismo. Os resultados e as inferências das experiências passadas encontram-se armazenados em procedimentos de operação-padrão, em regras profissionais e nas elementares regras de bolso da pessoa prática. Esses elementos do conhecimento histórico foram retratados tanto como formas de retrocesso irracional quanto como portadores de sabedoria e não é difícil especificar si- tuações ambientais em que qualquer uma dessas caracterizações seja adequada. O que é menos claro é se podemos modelar os processo de aprendizado institucional. Embora tenha-se aventado argumentos pouco precisos concernentes a que o aprendizado empírico conduzirá, no longo prazo, à descoberta e à adoção de estratégias mais favoráveis, pouco esforço teórico foi devotado para especificar-se precisamente as condições sob as quais o aprendizado a partir de experiências conduz a um comportamento mais favorável ou para relacionar tais condições às características da estrutura ou da vida institucional.

Consideremos o simples modelo de aprendizado a seguir (LEVINTHAL \& MARCH, 1982). Uma instituição de tomada de decisões aprende simultaneamente ao longo de três dimensões. Em primeiro lugar, ela modifica sua estratégia, ou seja, ela altera a probabilidade de fazer uma escolha em vez de outra entre as atividades alternativas disponíveis para ela. O sucesso subjetivo leva ao aumento da probabilidade de repetir uma escolha; o fracasso subjetivo leva a uma diminuição da probabilidade de repetir uma escolha (MARCH \& OLSEN, 1976). Em segundo lugar, uma instituição modifica suas competências, ou seja, ela altera a habilidade que possui nas várias atividades em que poderia engajar-se. A competência em uma atividade aumenta com a experiência que se acumula com ela; ela diminui com o tempo (PRESTON \& KEACHIE, 1964). Em terceiro lugar, uma instituição modifica suas aspirações, isto é, ela altera sua definição de sucesso subjetivo. As aspirações movem-se na direção de desempenhos passados (CYERT \& MARCH, 1963). Está claro que os fatores institucionais afetam diversas das características-chave de tal aprendizado. As taxas de aprendizado associadas aos três tipos de aprendizado são, em parte, uma função das características da instituição. O grau de acoplamento fraco em uma organização afeta a precisão com que as escolhas são feitas, os resultados observados, as aspirações expressas e as competências realizadas. Assim, ele pode ser expresso como formas variadas de ruído no processo. A inatividade organizacional afeta o grau de centralização na organização e assim a conexão entre as subunidades.

As três dimensões de aprendizado obviamente interagem. Por exemplo, o aprendizado sobre aspirações afeta a definição de sucesso subjetivo, o que, conseqüentemente, afeta o aprendizado so- 
bre as estratégias. O aprendizado sobre as competências afeta os resultados dos desempenhos, o que, conseqüentemente, afeta o aprendizado tanto sobre as estratégias quanto sobre as aspirações. $\mathrm{O}$ aprendizado sobre as estratégias afeta as escolhas, o que, conseqüentemente, afeta o aprendizado sobre as competências. Pode-se explorar o modelo a fim de descobrir-se as circunstâncias sob as quais ele alcança um equilíbrio e, entre aquelas circunstâncias, aquelas sob as quais ele alcança um nível ótimo. Ele também pode ser combinado em estruturas de aprendizado mais complexas em que as escolhas de uma instituição afetam os resultados de uma outra (por exemplo, competição e cooperação) e em que a instituição que aprende é, ela mesma, composta de subunidades de aprendizado.

Exemplo 3: latas de lixo. Os modelos da lata de lixo da escolha organizacional foram sugeridos como a representação de uma ordem temporal particular. Em sua forma mais comumente discutida na literatura, o modelo da lata de lixo supõe que problemas, soluções, tomadores de decisão e oportunidades de escolha são correntes independentes e exógenas que fluem por meio de um sistema (COHEN, MARCH \& OLSEN, 1972). Elas encontram-se conforme o tempo de sua chegada. Dessa maneira, as soluções estão primordialmente conectadas a problemas em função de sua simultaneidade; relativamente poucos problemas são resolvidos; na maior parte dos casos, escolhas são feitas, ou antes que quaisquer problemas sejam ligados a elas (omissão), ou depois de os problemas terem abandonado uma escolha para associarem-se a outra (abandono). Essa situação de extremo acoplamento fraco, chamada de estrutura aberta nas discussões originais sobre a lata de lixo, atraiu a maior parte da atenção na literatura e os estudos empíricos revelaram processos de decisão que parecem aproximar-se de tal estrutura aberta (MARCH \& OLSEN, 1976).

Entretanto, nem todas as situações de decisão são tão desestruturadas assim. Podemos caracterizar uma situação de escolha em termos de duas estruturas. A primeira é a estrutura de acesso, uma relação entre problemas (ou soluções) e oportunidades de escolha. A estrutura de acesso pode requerer, permitir ou não permitir que um problema particular, se ativado, seja anexado a uma escolha particular. A segunda estrutura é de decisão: uma relação entre tomadores de decisão e oportunidades de escolha. Essa estrutura pode requerer, per- mitir ou não permitir que um tomador de decisão particular participe da feitura de uma escolha particular. As estruturas de acesso e de decisão podem ser imaginadas em qualquer tipo de configuração arbitrária, porém duas formas especiais foram consideradas formalmente. Uma estrutura especializada é aquela decomposta em subestruturas abertas. Assim, uma estrutura de decisão especializada é aquela na qual se pode dividir as oportunidades de escolha e os tomadores de decisão em subgrupos e emparelhar os dois conjuntos de subgrupos de modo que cada tomador de decisão em um subgrupo particular de tomadores de decisão tenha acesso a toda oportunidade de escolha dentro do conjunto de oportunidades de escolha emparelhado, mas a nenhuma outra. Uma estrutura hierárquica é aquela que expande direitos de acesso como uma função da ordem hierárquica. Por exemplo, em uma estrutura de acesso hierárquico, problemas e escolhas são ordenados e cada problema tem acesso a escolhas da mesma classe ou de classe inferior. As diferenças feitas por essas estruturas foram notadas tanto formalmente (COHEN, MARCH \& OLSEN, 1972) quanto empiricamente (EGEBERG, 1981; OLSEN, 1983), porém o exame empírico e teórico de processos de lata de lixo em estruturas de acesso e de decisão que não são completamente abertos mal começou.

\section{IV.3. Fenômenos sutis e teorias simples}

Esses exemplos mal esgotam a lista. Observações empíricas de reputações de poder na política sugerem que tais reputações dependem pesadamente do lugar do indivíduo na estrutura política e das inferências sobre a relação entre preferências e resultados. Alguns modelos simples a respeito das relações dinâmicas entre reputações de poder, posições institucionais, preferências e resultados sociais proveriam um entendimento mais rico das maneiras pelas quais as reputações de poder afetam a política. As observações empíricas de surpresas pós-decisórias (isto é, desvios de resultados obtidos em comparação com resultados esperados) sugerem que existem diferenças sistemáticas entre as maneiras por que os indivíduos experimentam as conseqüências de suas ações e as maneiras por que as instituições fazem-no. Alguns modelos simples a respeito de expectativas institucionais, escolhas e avaliações pós-decisórias clarificariam as ocasiões em que se esperariam surpresas positivas ou negativas a partir da ação deliberada. 
O que caracteriza todos os exemplos, assim como outros que poderiam ser adicionados, é uma abordagem relativamente simples dos fenômenos institucionais. O neo-institucionalismo é freqüentemente expresso em termos do contraste entre a complexidade da realidade e as simplificações fornecidas pelas teorias existentes; mas a pesquisa teórica de uma perspectiva institucional não pode envolver a persecução de uma quantidade enorme de detalhes contextuais. Ela está constrangida pela capacidade da inteligência humana (e artificial) de fazer frente à complexidade e, embora essa capacidade pareça expandir-se com o tempo, a taxa de expansão continua a ser modesta em relação às demandas de uma teoria completamente contextual e institucional. Do ponto de vista da pesquisa teórica, conseqüentemente, o neo-institucionalismo é provavelmente mais bemvisto como uma busca de idéias alternativas que simplifiquem as sutilezas da sabedoria empírica de uma forma teoricamente útil.

\section{CONCLUSÃO}

O institucionalismo que consideramos não é nem uma teoria nem a crítica coerente de uma teoria. Ele é simplesmente o argumento de que a organização da vida política faz alguma diferença. Algumas das coisas que anotamos são fragmentos de idéias; outras são um tanto mais sistemáticas no desenvolvimento de um tema ou no relato de uma série de observações. Elas sustentam-se pela consciência de um conjunto de fenômenos que são mais facilmente observados do que explicados. Considerando que as idéias são consistentes, essa consistência é sustentada, em parte, pela ambigüidade. Muitas das idéias centrais parecem plausíveis e têm sido duráveis, mas a durabilidade plausível (como numerosos estudiosos da história do conhecimento observaram) não é nem necessária, nem suficiente para o bom senso.

O neo-institucionalismo é um preconceito de bases empíricas, uma asserção de que o que observamos no mundo é inconsistente com as maneiras pelas quais as teorias contemporâneas pedem-nos para falar. Como outros preconceitos no conhecimento, pode ser obstinado ou confuso, mas também pode ser uma continuação útil daquela confrontação branda entre o sábio e o perspicaz que descreve muito da história intelectual. Com a probabilidade de que seja o segundo - o que, é claro, não exclui a possibilidade de que seja também o primeiro -, tentamos traçar algumas implicações possíveis para a pesquisa teórica na Ciência Política. Elas são, no melhor dos casos, orientações teóricas sugeridas por uma avaliação favorável de uma tradição de pensamento institucionalista. Tal esforço é um pouco como tentar escrever um comentário útil sobre Heidegger na forma de um soneto de Shakespeare. Se ele tem alguma virtude, é a de tentar estimular a conversa sobre um corpo de pensamento sutil, de uma forma suficientemente ingênua a fim de instigar os tecnicamente proficientes.

James G. March (march@stanford.edu) é Professor Emérito da Universidade de Stanford (Estados Unidos).

Johan P. Olsen (j.p.olsen@arena.uio.no) é Professor Emérito da Universidade de Bergen (Noruega).

\section{REFERÊNCIAS BIBLIOGRÁFICAS}

AKERLOF, G. A. 1980. The Economics of Social Customs, of Which Unemployment May Be One Consequence. Quarterly Journal of Economics, Cambridge, Mass., v. 95, n. 2, p. 749-775, June.

ASHFORD, D. E. 1977. Political Science and Policy Studies : Towards a Structural Solution. Policy Studies Journal, London, v. 5, n. 1, p. 570-583, June.
AXELROD, R. 1980. More Effective Choice in Prisoner's Dilemma. Journal of Conflict Resolution, Thousand Oaks, v. 24, n. 1, p. 379-403.

AXELROD, R. \& HAMILTON, W. D. 1981. The Evolution of Cooperation. Science, Washington, D. C., v. 211, n. 4489, p. 1390-1396.

BACHRACH, P. \& BARATZ, M. 1962. The Two Faces of Power. American Political Science Review, Washington, D. C., v. 56, n. 4, p. 947952, Dec. 
BECKER, G. S. \& STIGLER, G. J. 1977. De gustibs non est disputandum. American Economic Review, Pittsburgh, v. 67, p. 7690.

BERGER, S. (ed.). 1981. Organizing Interests in Europe : Pluralism, Corporatism, and the Transformation of Politics. Cambridge, UK : Cambridge University.

BERKI, R. N. 1979. State and Society : An Antithesis of Modern Political Thought. In : HAYWARD, J. E. S. \& BERKI, R. N. (eds.). State and Society in Contemporary Europe. Oxford : M. Robertson.

BURNS, J. M. 1978. Leadership. New York : Harper \& Row.

COHEN, A. P. 1974. Two-Dimensional Man : An Essay on the Anthropology of Power and Symbolism in Complex Societies. London : Routledge.

COHEN, M. D. \& AXELROD, R. 1984. Coping with Complexity : The Adaptative Value of Changing Utility. American Economic Review, Pittsburgh, v. 74, p. 30-42.

COHEN, M. D.; MARCH, J. G. \& OLSEN, J. P. 1972. A Garbage Can Model of Organizational Choice. Administrative Science Quarterly, Ithaca, v. 17, n. 1, p. 1-25, Mar.

CROZIER, M. 1964. The Bureaucratic Phenomenon. Chicago : University of Chicago.

CYERT, R. M. \& MARCH, J. G. 1963. A Behavioral Theory of the Firm. Englewood Cliffs : Prentice-Hall.

DOWNS, A. 1957. An Economic Theory of Democracy. New York : Harper \& Row.

EASTON, D. 1968. Political Science. In : SILLS, D. L. (ed.). International Encyclopedia of the Social Sciences. V. 12. New York : Macmillan.

ECKOFF, T. \& JACOBSEN, K. D. 1960. Rationality and Responsibility in Administrative and Judicial Decision-Making . Copenhagen : Munksgaard.

EDELMAN, M. 1964. The Symbolic Uses of Politics. Urbana : University of Illinois.

EGEBERG, M. 1981. Stat of organisasjoner. Bergen : Universitetsforlaget.
ENDERUD, H. 1976. The Perception of Power. In : MARCH, J. G. \& OLSEN, J. P. (eds.). Ambiguity and Choice in Organizations. Bergen : Universitetsforlaget.

ETHEREDGE, L. S. 1976. The Case of the Unreturned Cafeteria Trays. Washington, D. C. : American Political Science Association.

EVANS, P.; RUESCHEMEYER, D. \& SKOCPOL, T. (eds.). 1983. Bringing the State Back In. Report of a Conference on Research Implications of Current Theories of the State. Unpublished manuscript.

FELDMAN, M. S. \& MARCH, J. G. 1981. Information as Signal and Symbol. Administrative Science Quarterly, Ithaca, v. 26, p. 171-186, June.

FRIEDMAN, M. 1953. Essays in Positive Economics. Chicago : University of Chicago.

GEERTZ, C. 1980. Negara : The Theater State in Nineteenth Century Bali. Princeton : Princeton University.

HANF, K. \& SCHARPF, F. (eds.). 1978. Interorganizational Policy Making : Limits to Coordination and Central Control. London : Sage.

HAYWARD, J. E. S. \& BERKI, R. N. (eds.). 1979. State and Society in Contemporary Europe. Oxford : M. Robertson.

HECLO, H. 1974. Modern Social Policies in Britain and Sweden. New Haven : Yale University.

HELLER, H. 1933 (1957). Political Science. In : SELIGMAN, E. R. A. \& JOHNSON, A. (eds.) Encyclopedia of the Social Sciences. New York : Macmillan.

HIRSCHEIFER, J. \& RILEY, J. G. 1979. The Analytics of Uncertainty and Information - An Expository Survey. Journal of Economic Literature, Pittsburgh, v. 17, n. 4, p. 13751421, Dec.

JESSOP, B. 1977. Recent Theories of the Capitalist State. Cambridge Journal of Economics, Oxford, v. 1, n. 4, p. 353-373, Dec.

KAHNEMAN, D. 1982. Bureaucracies, Minds, and the Human Engineering of Decisions. In : UNGSON, G. R. \& BRAUNSTEIN, D. N. 
(eds.). Decision Making : An Interdisciplinary Inquiry. Boston : Kent.

KAHNEMAN, D.; SLOVIC, P. \& TVERSKY, A. (eds.). 1982. Judgement under Uncertainty : Heuristics and Biases. Cambridge, UK : Cambridge University.

KATZENSTEIN, P. J. (ed.). 1978. Between Power and Plenty : Foreign Economic Policies of Advanced Industrial States. Madison : University of Wisconsin.

KJELBERG, F. 1975. Political Institutionalization. London : Wiley.

KRASNER, S. D. 1978. Defending the National Interest : Raw Materials, Investments and the US Foreign Policy. Princeton : Princeton University.

1984. Approaches to the State : Alternative Conceptions and Historical Dynamics. Comparative Politics, New York, v. 16, n. 2, p. 223-246, Jan.

KRIEGER, S. 1983. Mirror Dance. Philadelphia : Temple University.

KURZ, M. 1978. Altruism as an Outcome of Social Interaction. American Economic Review, Pittsburgh, v. 68, n. 2, p. 216-222, May.

LAEGREID, P. \& OLSEN, J. P. 1978. Byaakraft og beslutninger. Bergen : Universitetsforlaget.

LAFFERTY, W. M. 1981. Participation and Democracy in Norway. Oslo : Universitetsforlaget.

LAVE, C. A. \& MARCH, J. G. 1975. An Introduction to Models in the Social Sciences. New York : Harper \& Row.

LEVI, M. 1981. The Predatory Theory of Rule. Politics and Society, Thousand Oaks, v. 10, n. 4, p. 431-465.

LEVINTHAL, D. \& MARCH, J. G. 1982. A Model of Adaptative Organizational Research. Journal of Economic Behavior and Organization, Amsterdam, v. 2, p. 307-333, Dec.

LONG, N. 1958. The Local Community as an Ecology of Games. American Journal of Sociology, v. 64, n. 3, p. 251-261, Dec.

LUCE, R. D. \& RAIFFA, H. 1957. Games and Decisions. New York : Wiley.
MARCH, J. C. \& MARCH, J. G. 1978. Performance Sampling in Social Matches. Administrative Science Quarterly, 23, p. 434-453.

MARCH, J. G. 1962. The Business Firm as a Political Coalition. Journal of Politics, Cambridge, Mass., v. 24, n. 4, p. 662-678, Nov.

. 1966. The Power of Power. In : EASTON, D. (ed.). Varieties of Political Theory. Englewood Cliffs : Prentice-Hall.

1970. Politics and the City. In : ARROW, K.; COLEMAN, J. S.; DOWNS, A. \& MARCH, J. G. (eds.). Urban Processes as Viewed by the Social Sciences. Washington, D. C. : The Urban Institute.

1978. Bounded Rationality, Ambiguity, and the Engineering of Choice. Bell Journal of Economics, N. 9, p. 587-608.

1981. Decisions in Organizations and Theories of Choice. In : VAN DE VEN, A. H. \& JOYCE, W. F. (eds.). Perspectives on Organizational Design and Behavior. New York : Wiley.

MARCH, J. G. \& OLSEN, J. P. 1976. Ambiguity and Choice in Organizations. Bergen : Universitetsforlager.

1983. Organizing Political Life : What Administrative Reorganization Tells Us about Government. American Political Science Review, Washington, D. C., v. 77, n. 2, p. 281296, June.

MARCH, J. G. \& SHAPIRO, Z. 1982. Behavioral Decision Theory and Organizational Decision Theory. In : UNGSON, G. R. \& BRAUNSTEIN, D. N. (eds.). Decision Making : An Interdisciplinary Inquiry. Boston : Kent.

MARCH, J. G. \& SIMON, H. A. 1958. Organizations. New York : Wiley.

MASTERS, R. D. 1983. The Biological Nature of the State. World Politics, 35, p. 161-193.

MEYER, J. W. \& ROWAN, B. 1977. Institutionalized Organizations : Formal Structure as Myth and Ceremony. American Journal of Sociology, N. 83, p. 340-363.

NELSON, R. R. \& WINTER, S. G. 1982. An Evolutionary Theory of Economic Change. Cambridge, Mass. : Harvard University. 
NISBET, R. \& ROSS, L. 1980. Human Inference : Strategies and Shortcomings of Social Judgment. Englewood Cliffs : Prentice-Hall.

NISKANEN, W. A. 1971. Bureaucracy and Representative Government. Chicago : R. McNally.

NORDLINGER, E. 1981. On the Autonomy of the Democratic State. Cambridge, Mass. : Harvard University.

OLSEN, J. P. 1970. Local Budgeting : Decision Making or a Ritual Act? Scandinavian Political Studies, v. 5, n. A5, p. 85-118, Jan.

1981. Organizational Integration in Government. In : NYSTROM, P. \& STARBUCK, W. (eds.). Handbook of Organizational Design. V. 2. New York : Oxford University.

1983. Organized Democracy. Bergen : Universitetsforlaget.

OLSEN, J. P. \& SAETREN, H. 1980. Aksjoner og demokrati. Bergen : Universitetsforlaget.

OLSON, M. 1965. The Logic of Collective Action. Cambridge, Mass. : Harvard University.

PADGETT, J. F. 1981. Hierarchy and Ecological Control in Federal Budgetary Decision Making. American Journal of Sociology, Chicago, v. 87, n. 1, p. 75-129, July.

PATEMAN, C. 1970. Participation and Democratic Theory. Cambridge, UK : Cambridge University.

PFEFFER, J. 1981a. Management as Symbolic Action : The Creation and Maintenance of Organizational Paradigms. In : CUMMINGS, L. \& STAW, B. M. (eds.). Research in Organizational Behavior. V. 3. Greenwhich : JAI.

1981b. Some Consequences of Organizational Demography : Potential Impacts of an Aging Work Force on Formal Organizations. In : KIESLER, S. B.; MORGAN, J. N. \& OPPENHEIMER, V. K. (eds.). Aging : Social Change. New York : Academic.

PONDY, L. R. 1978. Leadership as a Language Game. In : MCCALL Jr., M. W. \& LOMBARDO, M. M. (eds.). Leadership. Durham : Duke University.

POTTER, A. L. 1979. Political Institutions, Political Decay and the Argentine Crisis of
1930. Doctoral dissertation in Political Science. Palo Alto : Stanford University.

PRESSMAN, J. L. \& WILDAVSKY, A. B. 1973. Implementation. Berkeley : University of California.

PRESTON, L. D. \& KEACHIE, E. C. 1964. Cost Functions and Progress Functions : An Integration. American Economic Review, Pittsburgh, v. 54, n. 2, p. 100-108, Mar.

ROBINS, R. S. 1976. Political Institutionalizatio$n$ and the Integration of Elites. Beverly Hills : Sage.

SCHARPF, F. W. 1977. Does Organization Matter? Task Structure and Interaction in the Ministerial Bureaucracy. In : BURACK, E. H. \& NEGANDHI, A. R. (eds.). Organizational Design : Theoretical Perspectives and Empirical Findings. Kent, Ohio : Kent State University.

SCHMITTER, P. \& LEHMBRUCH, G. (eds.) 1979. Trends toward Corporatist Intermediation. Beverly Hills : Sage.

SELZNICK, P. 1957. Leadership in Administration. Evanston : Northwestern University.

SHARPE, W. F. 1970. Portfolio Theory and Capital Markets. New York : McGraw-Hill.

SHEPSLE, K. \& WEINGAST, B. 1982. Institutionalizing Majority Rule : A Social Choice Theory with Policy Implications. American Economic Review, Pittsburgh, v. 73, n. 2, p. 367-372, May.

SIMON, H. A. 1957a. Administrative Behavior. $2^{\text {nd }}$ ed. New York : Macmillan.

1957b. Models of Man. New York : Wiley.

SKOCPOL, T. 1979. States and Social Revolutions : A Comparative Analysis of France, Russia, and China. Cambridge, UK : Cambridge University.

1980. Political Response to Capitalist Crises : Neo-Marxist Theories of the State and the Case of the New Deal. Politics and Society, v. 10 , n. 2, p. $155-201$.

SKOCPOL, T. \& FINEGOLD, K. State Capacity and Economic Intervention in the Early New Deal. Political Science Quarterly, New York, v. 97, n. 2, p. 255-278, Summer. 
SKOWRONEK, S. 1982. Building a New American State. Cambridge, UK : Cambridge University.

STEPHAN, A. C. 1978. The State and Society: Peru in Comparative Perspective. Princeton : Princeton University.

STIGLER, G. G. 1952. The Theory of Price. $2^{\text {nd }}$ ed. New York : Macmillan.

THERBORN, G. 1980. What Does the Ruling Class Do When It Rules? London : Verso.

TILLY, C. 1978. From Mobilization to Revolution. Reading, Mass. : Addison-Wesley.

TRIMBERGER, E. K. 1978. Revolution from Above : Military Bureaucrats and Development in Japan, Turkey, Egypt, and Peru. New Brunswick : Transaction.
TRIVERS, R. 1971. The Evolution of Reciprocal Altruism. Quarterly Review of Biology, Chicago, v. 46, n. 1, p. 35-57, Mar.

WATERSTONE, G. C. 1966. Order and Counterorder. Dualism in Western Culture. New York : Philosophical Library.

WILLIAMSON, O. E. 1978. Markets and Hierarchies. Analysis and Antitrust Implications. New York : Free.

WOLIN, S. 1960. Politics and Vision. Boston : Little, Brown.

WRIGHT, H. T. 1977. Recent Research on the Origin of the State. Annual Review of Anthropology, Palo Alto, n. 6, p. 379-397. 


\section{James G. March and Johan P. Olsen}

Contemporary theories of politics tend to portray politics as a reflection of society, political phenomena as the aggregate consequences of individual behavior, action as the result of choices based on calculated self-interest, history as efficient in reaching unique and appropriate outcomes, and decision making and the allocation of resources as the central foci of political life. Some recent theoretical thought in political science, however, blends elements of these theoretical styles into an older concern with institutions. This new institutionalism emphasizes the relative autonomy of political institutions, possibilities for inefficiency in history, and the importance of symbolic action to an understanding of politics. Such ideas have a reasonable empirical basis, but they are not characterized by powerful theoretical forms. Some directions for theoretical research may, however, be identified in institutionalist conceptions of political order. This is precisely the objective of the present article.

Keywords: neo-institutionalism; institutional autonomy; symbolic action; efficiency of action. 
NÉO-INSTITUTIONALISME: FACTEURS ORGANISATIONNELS DANS LA VIE POLITIQUE.

\section{James G. March et Johan P. Olsen}

Les théories politiques contemporaines ont tendance à présenter la politique comme un reflet de la société ; les phénomènes politiques comme les conséquences agrégées du comportement individuel ; l'action comme résultat de choix basés sur l'intérêt personnel réfléchi ; l’histoire comme étant efficace à portée de dénouement particuliers et adéquats et la prise de décisions et la distribution de ressources comme des centres essentiels de la vie politique. Néanmoins, une réflexion théorique récente en Science Politique associe des éléments de ces styles théoriques à un souci plus ancien concernant les institutions. Ce néo-nationalisme met en relief l'autonomie relative des institutions politiques, les possibilités d'incapacité dans l'histoire et l'importance de l'action symbolique en vue de comprendre la politique. Telles idées ont une assez bonne base empirique, mais ne se caractérisent pas par des formes théoriques puissantes. Pourtant, il est possible d'identifier quelques directions pour la recherche théorique dans les conceptions institutionalistes de l'ordre politique : voici notre objectif dans cet article.

MOTS-CLÉS : néo-institutionalisme ; autonomie des institutions; action symbolique; efficacité de l’action. 